\title{
Toll competition among congested roads
}

\author{
Eduardo Engel \\ Ronald Fischer \\ Alexander Galetovic
}

\section{SERIE ECONOMIA $\mathbf{N}^{\circ} \mathbf{5 4}$}

Abril 1999

\begin{abstract}
Centro de Economía Aplicada
Departamento de Ingeniería Industrial

Facultad de Ciencias Físicas y Matemáticas

Universidad de Chile
\end{abstract}




\title{
Toll Competition Among Congested Roads
}

\author{
Eduardo Engel, Ronald Fischer and Alexander Galetovic ${ }^{1}$
}

April, 1999

\begin{abstract}
A growing number of roads are currently financed by the private sector via Build-Operate-andTransfer (BOT) schemes. When the franchised road has no close substitute, the government must regulate tolls. Yet when there are many ways of getting from one point to another, regulation may be avoided by allowing competition between several franchise owners. This paper studies toll competition among private roads with congestion.

The paper derives two main results. First, we find sufficient conditions for the existence of an equilibrium in pure strategies with strictly positive tolls. Equilibrium congestion is less than optimal, which runs counter to what is expected from price competition. While a lower toll reduces the out-of-pocket cost paid by a user, it increases the congestion cost thereby reducing the drivers' willingness to pay for using the road. Franchise holders partially internalize congestion costs when setting tolls, which softens price competition. Second, when demand and the number of roads increase at the same rate, tolls converge to the socially optimal level — that is, in the limit equilibrium tolls are just enough to make each driver internalize the congestion externality.
\end{abstract}

Keywords: Private toll roads, congestion, competition.

JEL Classification: R41.

\footnotetext{
${ }^{1}$ The authors are at the Center of Applied Economics (CEA), Department of Industrial Engineering, University of Chile. Engel is also with the NBER and Visiting Professor at the Center for Research on Economic Development and Policy Reform, Stanford University. Address: Av. República 701, Santiago, Chile. E-mail: eengel@dii.uchile.cl, rfischer@dii.uchile.cl, agaleto@dii.uchile.cl. Financial support from the Mellon Foundation (Grant 9608), FONDECYT (Grants 1980658 and 1981188) and the Dirección de Investigación, Fac. Cs. Físicas y Matemáticas, University of Chile (to Fischer) is gratefully acknowledged.
} 


\section{Introduction}

Chronic budgetary problems have led many governments to franchise roads to private firms. In a typical deal a private franchise holder is granted the right to charge tolls for a fixed period of time. In exchange for the toll revenue, the franchise holder finances, builds, operates and maintains the road. ${ }^{2}$

When the franchised road has no close substitute, the government must regulate tolls. Yet when there are many ways of getting from one point to another, as often is the case in large cities, regulation may be avoided by allowing competition between several franchise owners. The purpose of this paper is to study the competitive game between road operators and to evaluate the welfare implications of toll competition. A pair of locations joined by several asymmetric roads is considered. Each road is subject to congestion and run by a different operator. Private road owners compete by setting tolls.

The paper has two main results. First, we find sufficient conditions for existence of a pure strategy equilibrium with strictly positive tolls. The franchise holder incurs no direct costs when one additional car uses the road. Nevertheless, while a lower toll reduces the out-of-pocket cost paid by a user, it increases the congestion cost thereby reducing the driver's willingness to pay for using the road. Franchise holders partly internalize congestion costs when setting tolls, which softens price competition. Even though franchise holders compete by choosing prices, the equilibrium is similar to the one that obtains in a standard Cournot game. The cost of congestion acts like the capacity constraint in Kreps and Scheinkman's (1983) two stage oligopoly game in which capacity is chosen in the first stage and firms compete in prices in the second stage. This runs counter to the intuition that price competition will lead to Bertrand outcomes and excessive congestion (see, for example, de Palma [1992]). Moreover, the traffic assignment between roads is generally inefficient.

The second result shows that increased competition brings tolls closer to the socially optimal level, even when roads are asymmetric, facility owners price strategically, and both the number of roads and demand increase at the same rate - that is, in the limit equilibrium tolls are just enough to make each driver internalize the congestion externality even when the ratio between the size of demand and the number of roads is kept constant.

\footnotetext{
${ }^{2}$ See Engel, Fischer and Galetovic (1997) for a discussion of highway franchising.
} 
This paper is related to the literature on road pricing pioneered by Walters (1961). ${ }^{3}$ Traditionally, this literature has studied road pricing as a standard planning problem. ${ }^{4}$ Exceptions are Viton (1995), who studies whether a private road can profitably compete with an untolled public road; and Verhoef, Nijkamp and Rietveld (1996), who consider the tolls set by a profit-maximizing private road owner competing with an untolled road. Our model generalizes the one developed in Verhoef et al. (1996) to study strategic toll setting by competing private road owners.

The paper also suggests that there is a close relation between the economics of franchised roads and the economics of clubs. ${ }^{5}$ Roads are subject to congestion, much like standard club goods. As in Scotchmer's (1985a, 1985b) analysis of club goods, this paper models the strategic interaction of road owners and looks for Nash equilibria. In the case of roads the analysis is simplified by Wardrop's (1952) characterization of equilibrium traffic assignments among roads. Unlike Scotchmer (1985a, 1985b), this paper considers asymmetric roads, since geographic constraints determine the characteristics of competing roads. For similar reasons this paper does not assume free entry, a point emphasized by Scotchmer.

The rest of the paper proceeds as follows. Section 2 presents the model. In section 3 we solve the problem of the social planner. Section 4 analyzes competition among roads. Section 5 studies the case where competition increases and finally, section 6 concludes.

\section{The model}

There are $n$ roads that join two locations. The marginal benefit of an additional trip when $Q$ trips have already been made is $B(Q) \geq 0$, with $B^{\prime}<0$, and

$$
Q=\sum_{i=1}^{n} q_{i}
$$

\footnotetext{
${ }^{3}$ See Hau (1992) for a survey and Mohring (1994) for a collection of the most important articles.

${ }^{4}$ For early contributions see Lévy-Lambert (1968) and Marchand (1968). Recent contributions are the series of papers by Arnott et al. (1990, 1993, 1994).

${ }^{5}$ See, for example, Berglas (1976, 1981), Berglas and Pines (1981), Boadway (1980) and Scotchmer (1985a, 1985b).
} 
where $q_{i}$ is the number of trips made on road $i$. We assume that traffic imposes no maintenance or other costs on the road operator. ${ }^{6}$ The cost of making one trip on road $i$ has two components. First, the toll charged by the road operator, $p_{i}$; second, the time cost of making a trip when $q_{i}$ cars are already on the road, $c_{i}\left(q_{i}\right)$, where $c_{i}>0, c_{i}^{\prime}>0$, and $c_{i}^{\prime \prime}>0$. Thus $p_{i}+c_{i}\left(q_{i}\right)$ is the generalized travel cost faced by each driver. As is well known since Wardrop (1952), in equilibrium the number of cars on road $i$ is determined by

$$
B(Q)=p_{i}+c_{i}\left(q_{i}\right)
$$

for all roads $i$; that is, users will enter roads until the marginal benefit of an additional trip equals the generalized travel cost in each of the $n$ roads. We are ready to examine the social planner's problem.

\section{The social planner}

In this section we solve the problem of a social planner that can choose both the total number of vehicles traveling, $Q$, and their distribution on alternative roads, $\left(q_{i}\right)_{i=1}^{n}$. The planner solves

$$
\max _{q_{1}, q_{2}, \ldots, q_{n}} \mathcal{S}\left(q_{1}, \ldots, q_{n}\right) \equiv \int_{0}^{\sum_{i=1}^{n} q_{i}} B(v) d v-\sum_{i=1}^{n} q_{i} c_{i}\left(q_{i}\right) .
$$

The first term is the sum of benefits that drivers obtain from $Q \equiv \sum_{i} q_{i}$ trips. The second term is the sum of the congestion costs borne by drivers. Since tolls redistribute income from users to the owner of the road, they do not affect social surplus directly. Next we show that the objective function (3) is concave and provide conditions for existence and uniqueness of a solution.

Proposition 3.1 The function $\mathcal{S}\left(q_{1}, \ldots, q_{n}\right)$ is strictly concave. Furthermore, if for all $i$

$$
\lim _{q_{i} \rightarrow \infty} c_{i}\left(q_{i}\right)+q_{i} c^{\prime}{ }_{i}\left(q_{i}\right)-B\left(q_{i}\right)>0,
$$

\footnotetext{
${ }^{6}$ It is straightforward to extend the present framework to include other costs internalized by each road operator such as road deterioration.
} 
then there exists a unique solution to (3), $q^{*} \equiv\left(q_{1}^{*}, \ldots, q_{n}^{*}\right){ }^{7}$

Proof: See the appendix.

Assume all traffic flows in the planner's solution are positive. It then follows from Proposition 3.1 that the first order sufficient conditions of this problem are

$$
\frac{\partial \mathcal{S}}{\partial q_{i}}=B\left(\sum_{j} q_{j}\right)-c_{i}-q_{i} c_{i}^{\prime}=0
$$

from where for all roads $i$

$$
B\left(Q^{*}\right)=c_{i}\left(q_{i}^{*}\right)+q_{i}^{*} c_{i}^{\prime}\left(q_{i}^{*}\right),
$$

with $Q^{*} \equiv \sum_{i} q_{i}^{*}$. That is, the benefit derived from the last trip must be equal to the sum of the private $\operatorname{cost} c_{i}$ and the congestion externality $q_{i} c_{i}^{\prime}\left(q_{i}\right)$ in all of the $n$ roads. From the equilibrium condition (2) and the optimality condition (6) it follows that the planner can implement the optimum by charging a set of tolls $\left(p_{i}^{*}\right)_{i=1}^{n}$ such that

$$
p_{i}^{*}=q_{i}^{*} c_{i}^{\prime}\left(q_{i}^{*}\right)
$$

\section{Oligopoly}

Consider now the case when each road is owned by a different operator and they compete for traffic by simultaneously choosing tolls. The owner of road $i$ takes $\left(p_{j}\right)_{j \neq i}$ as given and solves:

$$
\max _{p_{i}} \Pi_{i} \equiv p_{i} q_{i}
$$

In this section we prove existence of a Nash equilibrium in pure strategies and show that in equilibrium the number of vehicles on the road is less than optimal. Moreover, we show with an example that the traffic assignment is inefficient when congestion costs are asymmetric, i.e., the marginal cost of using a road (including congestion costs) is not equalized across roads.

\footnotetext{
${ }^{7}$ Condition (4) holds, in particular, when $\lim { }_{q \rightarrow \infty} B(q)=0$.
} 
We begin by proving a series of lemmas before getting to the main proposition of the section. Given $p \in \mathbb{R}^{n}$ we may interpret (2) as defining $q \in \mathbb{R}^{n}$ as a function of $p$. We show next that the corresponding inverse function $-q$ as a function of $p$-is well defined:

Lemma 4.1 Equation (2) implicitly defines $q$ as a function of $p$. Furthermore, this function is continuously differentiable in all coordinates.

Proof: See the appendix.

The following lemma confirms the signs one expects for the own and cross partial derivatives of traffic with respect to tolls. It also derives identities relating both kinds of derivatives.

Lemma 4.2 The functions $q_{i}(p)$, defined implicitly via (2), are such that (i) $\partial q_{i} / \partial p_{i}<0$ and (ii) $\partial q_{j} / \partial p_{i}>0$, for $j \neq i$. Furthermore, we have:

$$
\begin{aligned}
c^{\prime}{ }_{j}\left(q_{j}\right) \frac{\partial q_{j}}{\partial p_{i}} & =1+c^{\prime}{ }_{i}\left(q_{i}\right) \frac{\partial q_{i}}{\partial p_{i}}>0, \quad j \neq i, \\
B^{\prime}(Q) \sum_{k=1}^{n} \frac{\partial q_{k}}{\partial p_{i}} & =1+c^{\prime}{ }_{i}\left(q_{i}\right) \frac{\partial q_{i}}{\partial p_{i}}>0 .
\end{aligned}
$$

Proof: See the appendix.

Note that equation (8) implies that $c_{j}^{\prime}\left(q_{j}\right)\left(\partial q_{j} / \partial p_{i}\right)$ does not depend on $j, \forall j \neq i$.

Lemma 4.3 For all $i, c_{i}(q)+q c_{i}^{\prime}(q)$ is increasing in $q$.

Proof: Trivial, given the properties of the cost function.

The following result provides sufficient conditions for the existence of an equilibrium.

Proposition 4.1 Define $k_{i}=1 / c_{i}^{\prime}\left(q_{i}\right)$ and denote $S_{-i}(k)=\sum_{l \neq i} k_{l}$. Assume that $B(Q)$ is concave and that

$$
\left[S_{-i}(k)-\frac{1}{B^{\prime}(Q)}\right]^{3} \geq \sum_{j \neq i} \frac{c_{j}^{\prime \prime}\left(q_{j}\right)}{c_{i}^{\prime \prime}\left(q_{i}\right)} k_{j}^{3}, \quad \text { for all } i
$$

Then there exists an interior Nash equilibrium in pure strategies.

Proof: See the appendix for the proof and for non trivial examples where the above conditions hold.

We are now ready to prove the main result in this section. 
Proposition 4.2 Let $\left(p_{i}^{N}, q_{i}^{N}, Q^{N}\right)_{i=1}^{n}$ be the Nash equilibrium (assumed interior). Then: (i) $Q^{N}<$ $Q^{*}$. (ii) The traffic assignment across roads may be inefficient.

Proof: (i) From the equilibrium condition (2) we have that

$$
B\left(Q^{N}\right)-c_{i}\left(q_{i}^{N}\right)-q_{i}^{N} c_{i}^{\prime}\left(q_{i}^{N}\right)=p_{i}^{N}-q_{i}^{N} c^{\prime}{ }_{i}\left(q_{i}^{N}\right)
$$

Furthermore, an interior Nash equilibrium is a solution to the FOC of the profit equations (7):

$$
q_{i}^{N}+p_{i}^{N} \frac{\partial q_{i}}{\partial p_{i}}=0, \quad \forall i
$$

Using the first order condition (12) to substitute for $q_{i}$, in equation (11) leads to

$$
B\left(Q^{N}\right)-c_{i}\left(q_{i}^{N}\right)-q^{N} c_{i}^{\prime}\left(q_{i}^{N}\right)=p_{i}^{N}\left[1+c^{\prime}{ }_{i}\left(q_{i}^{N}\right) \frac{\partial q_{i}}{\partial p_{i}}\right]>0
$$

where the last inequality is due to (8). Now, suppose that, contrary to the proposition, $Q^{N} \geq Q^{*}$. Then there exists $i$ such that $q_{i}^{N} \geq q_{i}^{*}$ and

$$
B\left(Q^{N}\right)>c_{i}\left(q_{i}^{N}\right)+q_{i}^{N} c_{i}^{\prime}\left(q_{i}^{N}\right) \geq c_{i}\left(q_{i}^{*}\right)+q_{i}^{*} c_{i}^{\prime}\left(q_{i}^{*}\right)=B\left(Q^{*}\right)
$$

where the strict inequality follows from (13) and the weak inequality from Lemma 4.3. But since $B^{\prime}(Q)<0, Q^{N}<Q^{*}$, in contradiction with our initial assumption, which completes the first part of the proof.

(ii) To prove the second part of the proposition we present a counterexample that shows that the Nash equilibrium does not always lead to an efficient assignment of traffic. Let $c_{i}\left(q_{i}\right)=c_{i} q_{i}, i=1,2$ and $B(Q)=1-Q$. The corresponding demand functions for the roads are:

$$
q_{i}=\frac{c_{3-i}-\left(1+c_{3-i}\right) p_{i}+p_{3-i}}{\left(1+c_{1}\right)\left(1+c_{2}\right)-1}, \quad i=1,2
$$

Solving the first order conditions for each firm leads to the Nash equilibrium tolls:

$$
p_{i}=\frac{2 c_{3-i}\left(1+c_{i}\right)+c_{i}}{4\left(1+c_{1}\right)\left(1+c_{2}\right)-1}, \quad i=1,2 .
$$


Replacing in the expression for $q_{i}$ we can compute the total marginal cost $T M C_{i}=c_{i}\left(q_{i}\right)+q_{i} c_{i}^{\prime}\left(q_{i}\right)$. Performing the computations leads to $T M C_{i}=T M C_{j}$ if and only if $c_{i}=c_{j}$. Hence the traffic assignment in the example is inefficient unless congestion costs are identical across roads.

\section{$5 \quad$ Limit results}

In the previous section we have shown that the Nash equilibrium of the game between road owners is inefficient. In this section we show that as the economy becomes large, tolls converge to the socially optimal level. In order to get interesting results, we allow demand for roads to grow at the same rate as capacity expands. Nevertheless, drivers are free to choose any of the roads on any of the networks. Hence, our limit results depends solely on the reduction in the relative size of each individual owner with respect to the market and hence on her smaller ability to affect prices. We begin by considering the replication of complete road networks, where networks are composed of $n \geq 1$ roads with possibly different congestion costs. The first result is that the traffic in each network tends to the efficient assignment as the number of replications increases. ${ }^{8}$ Next we consider the special case where networks have only one road and extend the previous result by showing that convergence is monotonous in the number of roads.

Consider the case where there are $R$ identical networks, each one composed of $n$ (possibly asymmetric) roads. The following notation is used throughout:

- $q_{i}^{r}(R)$ : traffic on road $i$ in network $r$,

- $p_{i}^{r}(R)$ : the corresponding toll,

- $Q^{r}(R) \equiv \sum_{i=1}^{n} q_{i}^{r}(R)$ : total traffic on network $r$

- $Q_{R} \equiv \sum_{r=1}^{R} Q^{r}(R)$ : traffic over the $R$ networks.

Demand is assumed to grow at the same rate as capacity. That is, each time that a network is replicated another set of drivers with demand $B(Q)$ is added. Hence the marginal benefit function for the replicated network, denoted by $B_{R}(Q)$, is related to the marginal benefit function of an

\footnotetext{
${ }^{8} \mathrm{~A}$ similar result appears in Scotchmer (1985a) for club goods.
} 
individual network by

$$
B_{R}(Q) \equiv B\left(\frac{Q}{R}\right)
$$

Definition: A symmetric equilibrium satisfies $q_{i}(R) \equiv q_{i}^{r}(R), p_{i}(R) \equiv p_{i}^{r}(R)$ and $Q^{r}(R) \equiv Q(R)$ for all $i, r$.

The following proposition shows that when the number of replications is very large, each road in each network approximately carries the optimal number of users and charges the optimal toll.

Proposition 5.1 Assume the planner's solution, which trivially is independent of the number of replications, is interior. Then for sufficiently large $R$ there exists a unique interior symmetric equilibrium $\left(q_{i}(R), p_{i}(R), Q(R)\right)$, and

$$
\begin{array}{r}
\lim _{R \rightarrow \infty} q_{i}(R)=q_{i}^{*}, \\
\lim _{R \rightarrow \infty} p_{i}(R)=q_{i}^{*} c^{\prime}{ }_{i}\left(q_{i}^{*}\right) .
\end{array}
$$

Proof: Whenever it is not a source of confusion, we omit writing out explicit dependence on $R$.

From (2) we have $B_{R}\left(Q_{R}\right)=p_{j}^{r}+c_{j}\left(q_{j}^{r}\right)$, and since $B_{R}\left(Q_{R}\right)=B\left(Q_{R} / R\right)=B(Q)$, it follows that $B(Q)=p_{j}^{r}+c_{j}\left(q_{j}^{r}\right)$, which, by symmetry, can be written as

$$
B(Q)=p_{j}+c_{j}\left(q_{j}\right), \quad j=1, \ldots, n
$$

Symmetry also implies that we can write the following partial derivatives independently of the network:

$$
\begin{aligned}
& \frac{\partial q_{i}^{r}}{\partial p_{i}^{r}}=\frac{\partial q_{i}}{\partial p_{i}} \equiv d_{i}, \quad i=1, \ldots, n \\
& \frac{\partial q_{i}^{r}}{\partial p_{j}^{s}}=\frac{\partial q_{i}}{\partial p_{j}} \equiv d_{i j}, \quad s \neq r \text { or } s=r \text { and } j \neq i, \quad i, j=1, \ldots, n
\end{aligned}
$$

Thus $d_{i i}$ denotes the cross partial derivative of traffic with respect to tolls for the same road on different networks, while $d_{i}$ denotes the own price elasticity for any of the $R$ versions of road $i$. From Proposition 4.2 it follows that the former is positive while the latter is negative. 
¿From (8),

$$
d_{j i}=\frac{1+c^{\prime}{ }_{i}\left(q_{i}\right) d_{i}}{c^{\prime}{ }_{j}\left(q_{j}\right)}, \quad j, i=1, \ldots, n
$$

Applying (9) to the composite network consisting of $n R$ roads leads to

$$
\frac{1}{R} B^{\prime}(Q)\left[d_{i}+R \sum_{j \neq i} d_{j i}+(R-1) d_{i i}\right]=1+c_{i}^{\prime}\left(q_{i}\right) d_{i}, \quad i=1, \ldots, n
$$

where we used the fact that $B_{R}^{\prime}\left(Q_{R}\right)=B^{\prime}\left(Q_{R} / R\right) / R=B^{\prime}(Q) / R$. Now, substituting into (18) the expression for $d_{j i}$ derived in (17) we get:

$$
\frac{1}{R} B^{\prime}(Q)\left[d_{i}+R \sum_{j \neq i} \frac{1+c_{i}^{\prime}\left(q_{i}\right) d_{i}}{c_{j}^{\prime}\left(q_{j}\right)}+(R-1) \frac{1+c_{i}^{\prime}\left(q_{i}\right) d_{i}}{c_{i}^{\prime}\left(q_{i}\right)}\right]=1+c_{i}^{\prime}\left(q_{i}\right) d_{i}, \quad i=1, \ldots, n
$$

which, solving for $d_{i}$ leads to:

$$
d_{i}=-\frac{1}{c^{\prime}\left(q_{i}\right)}\left\{1-\frac{A_{i}(R)}{R}\right\}
$$

with

$$
A_{i}(R) \equiv \frac{\frac{1}{{c^{\prime}}_{i}\left(q_{i}\right)}}{\sum_{j=1}^{n} \frac{1}{c^{\prime}{ }_{j}\left(q_{j}\right)}-\frac{1}{B^{\prime}(Q)}}>0 .
$$

Since $B^{\prime}<0$ and $c^{\prime}{ }_{i}>0$, we have that

$$
|A(R)| \leq \frac{\frac{1}{c_{i}^{\prime}\left(q_{i}\right)}}{\sum_{j=1}^{n} \frac{1}{c_{j}^{\prime}\left(q_{j}\right)}} \leq 1
$$

and we can write:

$$
d_{i}=-\frac{1}{c^{\prime}\left(q_{i}\right)}\left\{1+O_{i}(1 / R)\right\}
$$

where $d_{i}$ and $c^{\prime}{ }_{i}$ depend on $R$ and $\lim _{R \rightarrow \infty} O_{i}(1 / R)=0, i=1, \ldots, n$.

Now the first order conditions can be written (using symmetry) as:

$$
q_{i}+p_{i} d_{i}=0
$$

Replacing (16) and (21) in the first order conditions and manipulating yields

$$
c_{i}\left(q_{i}\right)+q_{i} c^{\prime}{ }_{i}\left(q_{i}\right)-B(Q)=\left[B\left(Q-c_{i}\left(q_{i}\right)\right]\right) O_{i}(\alpha), \quad i=1, \ldots, n,
$$


where $\alpha \equiv 1 / R$. Next we extend the $O_{i}(\alpha)$ functions to all $\alpha \in[0,1]$ in such a way that the resulting functions are continuously differentiable and then apply the Implicit Function Theorem to the set of equations in (23) at $q_{i}=q_{i}^{*}$ and $\alpha=0$ (i.e., at the planner's solution). The proof that the corresponding Jacobian is non singular is analogous to that of Lemma 4.1. It follows that (23) has a unique solution for all $\alpha$ in a neighborhood of $\alpha=0$ (i.e., for all $R$ large enough) and, since the solution is continuous in $\alpha$, that the corresponding $q_{i}$ 's converge to $q_{i}^{*}$ as $\alpha$ tends to zero.

From (16) it follows that:

$$
p_{i}(R)=B\left(\sum q_{i}(R)\right)-c_{i}\left(q_{i}(R)\right)
$$

so that, by continuity of $B$ and $c_{i}$,

$$
\lim _{R \rightarrow \infty} p_{i}(R)=B\left(\sum q_{i}^{*}\right)-c_{i}\left(q^{*}\right)
$$

Comparing the above identity with the planner's first order condition it follows that $p_{i}(R)$ converges to $q_{i}^{*} c_{i}^{\prime}\left(q_{i}^{*}\right)$.

The previous result shows that the allocation of traffic in a road system where independent road owners set tolls converges to the efficient allocation as the capacity of each road becomes smaller in relation to size of the market. In the special case in which each "network" has a single road we can go further and show that convergence to the efficient allocation is monotonic.

Definition 5.1 Let $p_{1}(q)=B(q)-c_{1}(q)$. We denote the elasticity of demand in an economy with one road by $\eta_{1}(q)=p_{1}(q) /\left[q p_{1}^{\prime}(q)\right]$.

Proposition 5.2 Suppose each network consists of a single road, and that $\eta_{1}{ }^{\prime}(q) \geq 0$ and $\eta_{1}(q) \geq$ $-1 .{ }^{9}$ Then, under the same assumptions of the previous proposition, in the symmetric equilibrium, as the number of roads $R$ increases, prices and quantities tend monotonically to their efficient values.

Proof: We drop the subindex from $c_{1}$ in what follows. Since in this case (20) becomes

$$
A(R)=\frac{B^{\prime}(q)}{B^{\prime}(q)-c^{\prime}(q)}
$$

\footnotetext{
${ }^{9}$ Engel, Fischer and Galetovic (1998) show that $B^{\prime \prime} \leq 0$ is sufficient for both conditions on $\eta_{1}$ to hold.
} 
it follows from (19), after some manipulation, that:

$$
d_{1}=-\frac{1}{c^{\prime}(q)}\left(1-R^{-1}\right)+\frac{1}{\left[B^{\prime}(q)-c^{\prime}(q)\right]} R^{-1}
$$

We now replace (16) and (24) in the first order conditions (22) to obtain:

$$
q-[B(q)-c(q)]\left\{\frac{1}{c^{\prime}(q)}\left[1-R^{-1}\right]-\frac{1}{\left[B^{\prime}(q)-c^{\prime}(q)\right]} R^{-1}\right\}=0
$$

Next, since from the definition of $\eta_{1}$ and (2) it follows that

$$
\eta_{1}(q)=\frac{B(q)-c(q)}{q\left[B^{\prime}(q)-c^{\prime}(q)\right]}
$$

the preceding expression leads to:

$$
\left(1+\frac{\eta_{1}(q)}{R}\right) q c^{\prime}(q)=\left(1-\frac{1}{R}\right)[B(q)-c(q)]
$$

Multiplying (25) by $R$ and differentiating across with respect to $R$, we get:

$$
c(q)+q c^{\prime}(q)-B(q)=-L(q) \frac{d q}{d R},
$$

with

$$
L(q)=q c^{\prime}(q) \eta_{1}{ }^{\prime}(q)+\left[R+\eta_{1}(q)\right]\left[c^{\prime}(q)+q c^{\prime \prime}(q)\right]+(R-1)\left[B^{\prime}(q)-c^{\prime}(q)\right] .
$$

From the assumptions on $\eta_{1}(q)$ and $(27)$ it follows that $L(q)>0$. Also, the left hand side of (26) is negative by (13). Therefore (26) implies that $\frac{d q}{d R}>0$. And since (16) implies that

$$
\frac{d p}{d R}=\left[B^{\prime}(q)-c^{\prime}(q)\right] \frac{d q}{d R}
$$

we have that $\frac{d p}{d R}<0$, which completes the proof. 


\section{Conclusion}

There are two important conclusions from this paper. At first sight it would appear that, as in the case of Bertrand competition, toll competition between two roads that are substitutes will lead to tolls set at marginal cost, i.e., zero in our case. However, lowering tolls raises congestion costs for all users of the road and therefore does not lead to a complete switch of users to the road with the lowest toll. Hence, the owner of each road faces a demand curve that is not infinitely elastic. Thus our first result that competition yields tolls that are higher than optimal and traffic flows that are inefficiently small. The result is due to the capacity constraint in roads, i.e., it is related to the idea that a price game when there are capacity constraints does not lead to the Bertrand result but is closer to a Cournot equilibrium (see Kreps and Scheinkman [1983]).

It is interesting to note that a similar result holds for a toll road that is a substitute of a public untolled road. The owner of the tolled road will be able to exact a positive toll, given sufficient congestion on the alternative road. A decrease in congestion in the untolled road hurts the private road. Hence, its owner will oppose all attempts to increase the capacity of the untolled road. For example, in the case of the Dulles Greenway near Washington D.C., a toll road that joins Dulles Airport to Leesburg in Virginia, the owner of the road has opposed the expansion of competitive public freeways which are untolled. ${ }^{10}$

The second result shows that as the number of independently owned roads increases the increased number of participants in the market makes road system more competitive, even if demand increases at the same rate. In fact, in the limit both total traffic flow and traffic allocation will be efficient. This suggests that in some cases where there is more than one road joining two cities or parts of a city, toll competition may be a viable way of regulating private roads.

Finally, it is noteworthy to remark on the close relationship between the economic analysis of competition between private toll roads and competition between clubs, which may allow the transfer of results between these two areas.

\footnotetext{
${ }^{10}$ See Viton (1995) and Verhoef et al. (1996) for analyses of a private road competing with an untolled alternative.
} 


\section{References}

[1] Arnott, R., A. de Palma and R. Lindsey, "Economics of a Bottleneck," Journal of Urban Economics 27, 111-130, 1990

[2] Arnott, R., A. de Palma and R. Lindsey, "A Structural Model of Peak-Period Congestion: A Traffic Bottleneck with Elastic Demand," American Economic Review 83, 161-179, 1993

[3] Arnott, R., A. de Palma and R. Lindsey, "The Welfare Effects of Congestion Tolls with Heterogeneous Commuters," Journal of Transport Economics and Policy 28, 139-161, 1994

[4] Berglas, E., "On the Theory of Clubs," American Economic Review Papers and Proceedings, 116-121, 1976

[5] Berglas, E., "The Market Provision of Club Goods Once Again," Journal of Public Economics 15 389-393, 1981

[6] Berglas, E., and D. Pines, "Clubs, Local Public Goods and Transportation Models: A Synthesis," Journal of Public Economics 15, 141-162, 1981

[7] Boadway, R., "A Note on the Market Provision of Club Goods," Journal of Public Economics 13, 131-137, 1980

[8] Engel, E., R. Fischer and A. Galetovic, "Infrastructure Franchising and Government Guarantees," in T. Irwin et al. (eds.) Dealing With Public Risk in Private Infrastructure, Washington: The World Bank, 1997

[9] Engel, E., R. Fischer and A. Galetovic, "Least-Present-Value-of-Revenue Auctions and Highway Franchising," NBER Working Paper No 6689, 1998

[10] Hau, T., "Economic Fundamentals of Road Pricing: A Diagrammatic Analysis," PR Working Paper 1070, Washington: The World Bank, 1992

[11] Kreps, D. and J. Scheinkman, "Quantity Precommitments and Bertrand Competition Yield Cournot Outcomes," Bell Journal of Economics 14, 326-337, 1983

[12] Lévy-Lambert, H., "Tarification des Services a Qualité Variable: Application aux Péages de Circulation," Econometrica 36, 564-574, 1968 
[13] Marchand, M. "A Note on Optimal Tolls in an Imperfect Environment," Econometrica 36, $575-581,1968$

[14] Mas-Collel, A., M. Whinston and J.R. Green: Microeconomic Theory, New York: Oxford University Press, 1995.

[15] Mohring, H. (ed.), The Economics of Transport. Aldershot: Elgar, 1994

[16] de Palma, A., "A Game-Theoretic Approach to the Analysis of Simple Congested Networks," American Economic Review Papers and Proceedings, 494-500, 1992

[17] Scotchmer, S., "Profit Maximizing Clubs," Journal of Public Economics 27, 25-45, 1985a

[18] Scotchmer, S., "Two-Tier Pricing of Shared Facilities in a Free Entry Equilibrium," Rand Journal of Economics 16, 456-472, 1985b

[19] Verhoef, E., P. Nijkamp and P. Rietveld, "Second-Best Congestion Pricing: The Case of an Untolled Alternative" Journal of Urban Economics 40, 279-302, 1996

[20] Viton, P., "Private Roads," Journal of Urban Economics 37, 260-289, 1995

[21] Walters, A. "The Theory and Measurement of Private and Social Cost of Highway Congestion," Econometrica 29, 676-699, 1961

[22] Wardrop, J., "Some Theoretical Aspects of Road Traffic Research," Proceedings of the Institute of Civil Engineers 1, 325-378, 1952 


\section{APPENDIX}

\section{Proof of Proposition 4.1}

To the notation introduced when stating the result add:

$$
\begin{aligned}
S(k) & \equiv \sum_{l=1}^{n} k_{i}, \\
\tilde{B} & \equiv \frac{1}{B^{\prime}\left(\sum_{k=1}^{n} q_{k}\right)}, \\
A_{i} & \equiv \frac{k_{i}}{S(k)-\tilde{B}}, \\
\gamma_{i} & \equiv \frac{c_{i}^{\prime \prime}\left(q_{i}\right)}{\left[c_{i}^{\prime}\left(q_{i}\right)\right]^{3}}, \\
S(\gamma) & \equiv \sum_{l=1}^{n} \gamma_{i}, \\
\beta^{*} & \equiv-\frac{B^{\prime \prime}\left(\sum_{l=1}^{n} q_{l}\right)}{\left[B^{\prime}\left(\sum_{l=1}^{n} q_{l}\right)\right]^{2}} .
\end{aligned}
$$

Some patient, but straightforward calculations then show that:

$$
\begin{aligned}
\frac{\partial q_{i}}{\partial p_{i}} & =-k_{i}\left(1-A_{i}\right), \quad i=1, \ldots, n, \\
\frac{\partial q_{l}}{\partial p_{i}} & =k_{l} A_{i}, \quad l \neq i, i=1, \ldots, n, \\
\frac{\partial k_{j}}{\partial p_{i}} & =-\gamma_{j} A_{i}, \quad j \neq i, i=1, \ldots, n ; \\
\frac{\partial k_{i}}{\partial p_{i}} & =\gamma_{i}\left(1-A_{i}\right), \quad i=1, \ldots, n ; \\
\sum_{l=1}^{n} \frac{\partial k_{l}}{\partial p_{i}} & =\gamma_{i}-S(\gamma) A_{i}, \\
k_{i}-S(k) A_{i} & =\frac{-k_{i} \tilde{B}}{\sum_{l=1}^{n} k_{l}-\tilde{B}}>0, \\
\sum_{l=1}^{n} \frac{\partial q_{l}}{\partial p_{i}} & =-\left[k_{i}-S(k) A_{i}\right]<0, \\
\frac{\partial \tilde{B}}{\partial p_{i}} & =-\beta^{*}\left[k_{i}-S(k) A_{i}\right], \\
\frac{\partial A_{i}}{\partial p_{i}} & =\frac{A_{i}}{k_{i}}\left\{\gamma_{i}\left(1-A_{i}\right)-A_{i}\left[\gamma_{i}-S(\gamma) A_{i}\right]-\beta^{*} A_{i}\left[k_{i}-S(k) A_{i}\right]\right\} .
\end{aligned}
$$


Next we prove strict concavity of the profit function of the $i$-th road's owner. This implies the existence of a Nash equilibrium in pure strategies (see Mas-Collel, Whinston and Green, 1995, p. $260)$.

Denoting profits of firm $i$ by $\Pi_{i}\left(p_{i}\right)$ we have that:

$$
\frac{\partial^{2} \Pi_{i}}{\partial p_{i}^{2}}=2 \frac{\partial q_{i}}{\partial p_{i}}+p_{i} \frac{\partial^{2} q_{i}}{\partial p_{i}^{2}}
$$

Since $\partial q_{i} / \partial p_{i}<0$, a sufficient condition for strict concavity of the profit function (and therefore existence of a Nash equilibrium) is that $\partial^{2} q_{i} / \partial p_{i}^{2} \leq 0$.

A calculation based on the expressions derived above shows that:

$$
\frac{\partial^{2} q_{i}}{\partial p_{i}^{2}}=-\gamma_{i}\left(1-A_{i}\right)^{3}+\left[S(\gamma)-\gamma_{i}\right] A_{i}^{3}-\beta^{*}\left[k_{i}-S(k) A_{i}\right] A_{i}^{2}
$$

From (33) it follows that $k_{i}-S(k) A_{i}>0$.

Some patient algebra shows that

$$
\gamma_{i}\left(1-A_{i}\right)^{3}-\left[S(\gamma)-\gamma_{i}\right] A_{i}^{3} \geq 0
$$

if and only if

$$
\frac{\gamma_{i}}{S_{-i}(\gamma)} \geq\left[\frac{k_{i}}{S_{-i}(k)+|\tilde{B}|}\right]^{3},
$$

where $S_{-i}(k) \equiv \sum_{j \neq i} k_{j}, S_{-i}(\gamma)$ analogous.

And since $\gamma_{i}=k_{i}^{3} c_{i}^{\prime \prime}$, where $c_{i}^{\prime \prime}$ is evaluated at $q_{i}$, condition (38) is equivalent to (10). It now follows from (37) that a sufficient condition for strict concavity of the profit function is that $B^{\prime \prime} \leq 0$ (so that $\beta^{*} \geq 0$ ) and (37), thereby concluding the proof.

Next some particular cases where the assumptions of Proposition 4.1 hold are presented. In the linear case $\partial^{2} q_{i} / \partial p_{i}^{2}=0$, so that $\Pi_{i}$ is strictly concave without a further do. The case of quadratic time-cost is more interesting. Assume

$$
c_{i}\left(q_{i}\right)=\alpha_{0}^{(i)}+\alpha_{1}^{(i)} q_{i}+\frac{1}{2} \alpha_{2}^{(i)} q_{i}^{2}
$$


with $\alpha_{0}^{(i)}>0, \alpha_{1}^{(i)}>0$ and $\alpha_{2}^{(i)}>0$, for all $i^{11}$

Define $\eta$ via:

$$
\eta \equiv \frac{\max _{i} \alpha_{2}^{(i)}}{\min _{i} \alpha_{2}^{(i)}}
$$

Then a sufficient condition for (10) to hold is:

$$
|\tilde{B}|^{3} \geq(\eta-1) \sum_{j \neq i} k_{j}^{3}, \quad \text { for all } i
$$

Two particular cases are of interest. First, when all $\alpha_{2}^{(i)}$ 's are identical. In this case $\eta=1$ and existence follows for any function $B(Q)$ that is concave and decreasing. Second, if $B(Q)=B_{0}-B_{1} Q$, with $B_{0}>0, B_{1}>0$, then Proposition 4.1 implies that

$$
\frac{1}{B_{1}^{3}} \geq(\eta-1) \sum_{j \neq i} \frac{1}{\left[\alpha_{1}^{(j)}\right]^{3}}, \quad \text { all } i
$$

is sufficient for existence of a Nash equilibrium.

\section{Proof of Proposition 3.1}

Let $1_{n, n}$ and $D\left(\lambda_{1}, \ldots, \lambda_{n}\right)$ denote, respectively, a $n$ by $n$ matrix with all elements equal to 1 and a diagonal matrix with $i$-th element on the diagonal equal to $\lambda_{i}$. A straightforward calculation shows that the Hessian of $S$ may be written as

$$
H=k 1_{n, n}-D\left(\lambda_{1}, \ldots, \lambda_{n}\right)
$$

where $k \equiv B^{\prime}\left(\sum q_{i}\right)$ and $\lambda_{j} \equiv 2 c_{j}^{\prime}\left(q_{j}\right)+q_{j} c_{j}^{\prime \prime}\left(q_{j}\right)$.

Given a column vector $x^{\prime}=\left(x_{1}, \ldots, x_{n}\right)$ we have that

$$
x^{\prime} H x=k\left(\sum_{i} x_{i}\right)^{2}-\sum_{i} \lambda_{i} x_{i}^{2} .
$$

Since $k<0$ and all $\lambda_{j}>0$, it suffices that one of the $x_{i}$ 's differ from zero to have $x^{\prime} H x<0$. Thus $\mathcal{S}$ is strictly concave.

\footnotetext{
${ }^{11}$ The non-trivial assumption is $\alpha_{1}^{(i)}>0$, we want $c_{i}^{\prime}(0)>0$.
} 
Since $B^{\prime}<0$, we have that

$$
\frac{\partial \mathcal{S}}{\partial q_{i}}=B\left(\sum_{j=1}^{n} q_{j}\right)-c_{i}\left(q_{i}\right)-q_{i} c_{i}^{\prime}\left(q_{i}\right) \leq B\left(q_{i}\right)-c_{i}\left(q_{i}\right)-q_{i} c_{i}^{\prime}\left(q_{i}\right) .
$$

It then follows from assumption (4) that there exist $\bar{q}_{1}, \ldots, \bar{q}_{n}$ such that the partial derivative evaluated at $q=\left(q_{1}, \ldots, q_{n}\right)$ is negative if any of the $q_{i}$ 's is larger than the corresponding $\bar{q}_{i}$. Hence we may restrict maximization of $\mathcal{S}$ to a compact subset of the positive orthant. Since a continuous function over a compact set has a maximum, it follows that $\mathcal{S}$ has a maximum. Due to strict concavity of $\mathcal{S}$ this maximum, denoted by $q^{*}$, is unique.

\section{Proof of Lemma 4.1}

A straightforward calculation shows that the Jacobian matrix corresponding to $p$ as a function of $q$ is of the form

$$
J \equiv k 1_{n, n}-D\left(\mu_{1}, \ldots, \mu_{n}\right)
$$

where the notation is the same as in the proof of Proposition 3.1 and $\mu_{i}=c_{i}^{\prime}\left(x_{i}\right)>0, i=1, \ldots, n$.

Denote the $i$-th column of the Jacobian matrix by $J_{i}$. To show that the Jacobian is non singular, we show that if $\alpha_{1}, \ldots, \alpha_{n}$ are real numbers such that $\sum_{i} \alpha_{i} J_{i}=0_{n}$, where $0_{n}$ denotes the vector in $\mathbb{R}^{n}$ with all coordinates equal to zero, then all the $\alpha_{i}$ 's are equal to zero.

A straightforward calculation shows that $\sum_{i} \alpha_{i} J_{i}=0_{n}$ implies that:

$$
k\left(\sum_{i} \alpha_{i}\right)=\alpha_{1} \mu_{1}=\ldots=\alpha_{n} \mu_{n}
$$

Hence:

$$
k\left(\sum_{i} \alpha_{i}\right) \frac{1}{\mu_{j}}=\alpha_{j}, \quad j=1, \ldots, n
$$

Summing over $j$ leads to:

$$
k\left(\sum_{i} \alpha_{i}\right) \sum_{j} \frac{1}{\mu_{j}}=\sum_{j} \alpha_{j} .
$$

Since all $\mu_{j}$ are positive, it follows from (42) that all $\alpha_{i}$ have the same sign. If all $\alpha_{i}$ are strictly 
positive or all $\alpha_{i}$ are strictly negative, it follows from (43) that

$$
k \sum_{j} \frac{1}{\mu_{j}}=1
$$

which cannot hold since $k<0$ and the $\mu_{j}>0$. It follows that all $\alpha_{i}=0$.

Having shown that the Jacobian is non singular, we may now apply the Implicit Function Theorem to conclude that the inverse function is well defined and differentiable.

\section{Proof of Lemma 4.2}

From (2), $p_{j}+c_{j}\left(q_{j}\right)=p_{i}+c_{i}\left(q_{i}\right), j \neq i$. Differentiating with respect to $p_{i}$ leads to the identity in (8). Differentiating both sides of (2) with respect to $p_{i}$ leads to the identity in (9).

The two identities we just proved imply that:

$$
c^{\prime}{ }_{j}\left(q_{j}\right) \frac{\partial q_{j}}{\partial p_{i}}=B^{\prime}(Q) \sum_{k=1}^{n} \frac{\partial q_{k}}{\partial p_{i}}, \quad j \neq i
$$

Next we prove (i) and (ii). From the identity in (8) and the assumption that all $c^{\prime}{ }_{j}>0$ we have that all $\partial q_{j} / \partial p_{i}$ have the same sign, $j \neq i$. If this common sign were negative, (8) implies that $\partial q_{i} / \partial p_{i}<0$ and the left hand side of (44) would be negative while the corresponding right hand side was positive. If all $\partial q_{j} / \partial p_{i}$ were equal to zero, $j \neq i$, then (44) and the assumption that $B^{\prime}<0$ imply that $\partial q_{i} / \partial p_{i}=0$. Yet then the right hand side of (8) would be positive while the left hand side is zero. We conclude that $\partial q_{j} / \partial p_{i}>0$ for all $j \neq i$. It then follows from (44) that $\partial q_{i} / \partial p_{i}<0$, for otherwise the left hand side of (44) would be positive while the right hand side was negative. We have thus shown (i) and (ii). The inequalities in (8) and (9) now follow trivially. 